\title{
Using MIMIC Modeling to Identify Dimensions of Self-Regulation in Cerebral Palsy
}

\author{
Ioannis Agaliotis, Panagiotis Varsamis* \\ Department of Educational and Social Policy, University of Macedonia, Thessaloniki, Greece \\ Email: *varsamis@uom.edu.gr
}

How to cite this paper: Agaliotis, I., \& Varsamis, P. (2019). Using MIMIC Modeling to Identify Dimensions of Self-Regulation in Cerebral Palsy. Psychology, 10, 799-818. https://doi.org/10.4236/psych.2019.106052

Received: April 2, 2019

Accepted: May 11, 2019

Published: May 14, 2019

Copyright $\odot 2019$ by author(s) and Scientific Research Publishing Inc. This work is licensed under the Creative Commons Attribution International License (CC BY 4.0).

http://creativecommons.org/licenses/by/4.0/

\section{(c) (i) Open Access}

\begin{abstract}
As long as physical disability is considered in terms of a continuous, dynamic, and dialectical relationship among personal and environmental factors, task characteristics will play an important role. The main purpose of this study is to confirm levels of motivation and self-regulation in students with Cerebral Palsy when confronted with an adapted ball throwing task. Using the dynamic approach of Self-Regulated Learning, a theory-driven Multiple Indicators and Multiple Causes model was eventually qualified. It comprised four levels of functioning, namely goal-setting, motor performance, efficacy beliefs, and self-reflections. These facets were greatly influenced by intellectual functions, hand functions, initial goals, coping self-efficacy, and throwing distance. Results underscore the role of disability and personal factors. Further research should expand on personal characteristics and focus on the longitudinal, i.e., developmental, examination for the proposed causal effects.
\end{abstract}

\section{Keywords}

ICF-CY, Goal-Setting, Self-Evaluation, Path Analysis, Special Education

\section{Introduction}

Cerebral Palsy (CP) describes a group of congenital disorders that adversely thwart psychomotor-and frequently perceptual and cognitive-features of development in the affected children. Although the causing events lead to $\mathrm{CP}$ change over the years (Stavsky et al., 2017), its incidence is relatively stable over time, amounting to 2 - 4 per 1000 live births, depending on the continent and country measured (e.g. Blair, Cans, \& Sellier, 2018; Christensen et al., 2014; EURO-PERISTAT, 2008). Thus, CP constitutes the most frequent movement disability in childhood (Graham et al., 2016; Paulson \& Vargus-Adams, 2017). 
According to the current definition (Rosenbaum, Paneth, Leviton, Goldstein, \& Bax, 2007: p. 9), "Cerebral palsy describes a group of permanent disorders of the development of movement and posture, causing activity limitation, that are attributed to non-progressive disturbances that occurred in the developing fetal or infant brain. The motor disorders of cerebral palsy are often accompanied by disturbances of sensation, perception, cognition, communication, and behaviour, by epilepsy and by secondary musculoskeletal problems". In most countries, the age of final diagnosis, i.e. formal registration, is two to five years (Blair \& Cans, 2018). Therefore, the difference between CP and children's Traumatic Brain Injury (TBI) does not rely so much on the age of acquiring a brain/motor disorder, but rather focuses on the conceptional consideration of TBI as an abruptly acquired impairment after a period of functional intactness (P. Rosenbaum, personal communication, September 15, 2018), which needs immediate rehabilitation, if not full recovery.

In consensus with the above-mentioned definition, $\mathrm{CP}$ refers to a heterogeneous group of complex developmental disruptions. Equally complex is the classification of the forms of CP (Rosenbaum et al., 2007). For example, people with CP can be characterized as presenting spasticity (unilateral or bilateral), dyskinesia (dystonic or choreo-athetotic), ataxia, or mixed forms, or other non-classifiable forms, as far as disorders of muscle tone are concerned (Surveillance of Cerebral Palsy in Europe, 2002; Graham et al., 2016). In terms of anatomical location, forms of quadriplegia, of diplegia, and hemiplegia are often encountered, while the forms of triplegia and monoplegia are considered as rare. However, over the last two decades, great interest manifested in determining performance levels of people's functional ability. These efforts aimed to create a worldwide classification language and to facilitate reliable longitudinal monitoring of $\mathrm{CP}$ characteristics (e.g., WHO, 2007).

This shift signifies the need to comprehend the wide range of everyday expressions of CP. Hence, the biopsychosocial model of the International Classification of Functioning for Children and Youth (ICF-CY, cf. WHO, 2007) gained importance. Being an inherently dynamic and ecosystemic model, it provides a comprehensive framework of interdependent factors, which contributes to the understanding of human functioning, health and wellness (McDougall, Wright, \& Rosenbaum, 2010; Rosenbaum \& Stewart, 2004). As a result, several interconnections among cerebral lesions, cognitive development and executive functions have been identified in people with CP (e.g., Bottcher, 2010; Laporta-Hoyos et al., 2017). Furthermore, cerebral lesions were found to cause disrupted psychomotor performance and activity limitations in many life domains (e.g., Bjornson, Zhou, Stevenson, \& Christakis, 2013; Varsamis \& Agaliotis, 2015). However, empirical findings do not suggest a generalized decline of functions, but merely demonstrate the negative effects of cerebral dysfunctions on specific variables of cognitive, executive, psychomotor, and psychosocial functioning (see also Varsamis \& Agaliotis, 2011; Palisano et al., 2009). At the same time, other compo- 
nents of the ICF-CY model may remain unaffected. A case in point is that when an adequate gross motor functionality is combined with positive attitudes/beliefs and family's support, people with CP can greatly elevate their participation in physical and recreational activities (Shikako-Thomas et al., 2013). Of course, these reports on $\mathrm{CP}$ are only indicative and they do not claim completeness of all available findings on the relationship between the ICF-CY factors.

Overall, CP is frequently approached, both in therapy and in education, as a continuous, dynamic, and dialectical balance among critical formative factors (Huang, 2018; Norwich, 2016). Consequently, disturbances in physical, cognitive etc. intactness, reductions of expected activity and restrictions of social participation may become particularly evident in the presence of thwarting context factors, meaning that-for the interacting partners-important discrepancies among individual behaviors, social expectations and requirements of a task may occur (see also Davis \& Burton, 1991; Newell \& Jordan, 2007; Hutzler, 2007). Conversely, if formative factors have a positive impact, strengths and capabilities of persons with CP are foregrounded (WHO \& World Bank, 2011).

In recent decades, researchers from different fields, such as psychology, rehabilitation, therapy, special education and adapted physical activity, recognized that among the factors contributing to the daily expression of a disability, a prominent role is played by the individual's innate development forces (Ryan \& Deci, 2017). Accordingly, people are organismically predisposed to self-organization, self-regulation, and self-determination, in order to meet their basic biological and psychological needs (Shogren \& Wehmeyer, 2016). Therefore, cognitive-affective processes, such as aspiration formation, self-determined choice, sense of volition, intentional planning, goal-setting, problem-solving, self-observation, and self-evaluation, are being strongly connected to effective learning and skills acquisition (e.g., Cleary, Callan, \& Zimmerman, 2012; Murayama et al., 2013; Palisano et al., 2011; Saebu, Sørensen, \& Halvari, 2013; Wehmeyer, Yeager, Bolding, Agran, \& Hughes, 2003).

In children and young people with $\mathrm{CP}$, preferences for participation in physical activities, elements of mastery motivation, facets of self-regulation and processes of self-evaluation are usually primarily affected by psychomotor disorders and executive dysfunctions (e.g., Miller, Ziviani, \& Boyd, 2013; Schuengel et al., 2006; Varsamis \& Agaliotis, 2011, 2015; Varsamis \& Papadopoulos, 2014). Undoubtedly, there are some secondary negative effects on motivation and self-efficacy resulting from the accumulated negative experiences, as people with $\mathrm{CP}$ are confronted with daily locomotor and psychomotor challenges (e.g., van der Slot et al., 2010). However, people with CP are able to learn motor sequences at their own pace, acquire new motor skills and gradually increase the attainment of their goals (Gofer-Levi, Silberg, Brezner, \& Vakil, 2013; Sharif, Hemayattalab, Sayyah, Hemayattalab, \& Bazazan, 2015; Varsamis, 2005).

The hitherto juxtaposition of theoretical models and research findings shows firstly, that CP's primary disability characteristics (i.e., impairments) and 
attributes of the person (e.g., motivation) are instrumental in forming everyday functionality. These factors should be taken into account, even if one studies people with $\mathrm{CP}$ in individual tasks using the microanalytical approach. In this direction, researchers acknowledge that some more stable self-regulation, trait-like, characteristics influence situative courses of action (Cleary \& Platten, 2013). Secondly, people with CP obviously need more time and practice, in order to acquire psychomotor skills, accompanied with the appropriate support from their teachers. It is therefore necessary to provide adapted tasks, space for participatory decisions and the needed time for self-determined exploration via repeated trying, setting own realistic goals, persisting on goal-performance pursuits and enabling self-improvement (e.g., Varsamis, 2005; Varsamis \& Agaliotis, 2011). Undoubtedly, psychomotor tasks must be principally doable with respect to the current physical and cognitive capabilities of people with CP (Varsamis \& Agaliotis, 2015). In addition, settings and tasks that attract participants' genuine, i.e., intrinsic, interest, can lay the basis for need satisfaction and self-determination (Ryan \& Deci, 2017).

Despite the increased research interest in self-regulation, empirical findings for people with $\mathrm{CP}$ are rather scarce. Thereby, evidence is lacking to critically evaluate the effectiveness of various theoretical-let alone research-models. In the present study, the dynamic approach of Self-Regulating Learning is primarily adopted (Cleary, Durning, \& Artino, 2016). At the same time, the role of selected physical, cognitive, and psychological functions was added (Huang, 2018). The purpose of this study is, on the one hand, to integrate the above factors into a single structural model, and, on the other hand, to determine the levels of self-regulation, when young people with $\mathrm{CP}$ are confronted with an adapted psychomotor task. The identification of complex self-regulatory levels adds to the understanding of psychomotor exploration procedures and of skills acquirement in this special sample. Moreover, useful aspects for psycho-pedagogical and psychomotor interventions may be brought to light.

\section{Method}

\subsection{Participants}

Participants were targeted by using a convenience, but also purposive, sampling method (Patton, 2015). We put effort in concentrating a homogenous sample, as we developed specific inclusion criteria (e.g., Palinkas, Horwitz, Green, Wisdom, Duan, \& Hoagwood, 2015). According to these criteria: 1) Participants were diagnosed by an official medical center as presenting congenital Cerebral Palsy. 2) Participants have no or mild to moderate difficulties in cognitive functions (classes 0 to 2 of the code b117 from the ICF-CY, WHO, 2007, cf. Varsamis \& Agaliotis, 2015). 3) Thus, participants were able to form and to communicate both decisions and self-appraisals, implying that participants had an adequately effective communication (Classes I to III of the Communication Function Classification System (CFCS, Hidecker et al., 2011). 4) Participants could throw or 
just roll a soft lightweight ball to a surface target, while sitting in a school chair or in their own wheelchair. Consequently, participants could act differently, some bending towards the target, and some pushing firmly against their seat back. Hence, participants from all classes of the Gross Motor Function Classification System-Expanded \& Revised (GMFCS-E \& R, Palisano, Rosenbaum, Bartlett, \& Livingston, 2008) could be enrolled. 5) For achieving sample homogeneity, persons who had to use assistive equipment (e.g., a bowling ramp) were not included. Consequently, persons who have extreme difficulties to handle objects, i.e., level V of the Manual Ability Classification System (MACS, Eliasson et al., 2006) were not integrated. 6) To further ensure sample homogeneity, only schoolchildren from special secondary education schools and institutions entered the sample. According to the Greek legislation, secondary special schools include students of nominal ages 13 to 25 years. 7) Besides consent provided by schools and parents, the participation of all students was voluntary, after the research protocol was explained to them. Confidentiality, dignity and all rights of the individuals and the groups (schools), were guaranteed. Our study conforms to the standards of the Economic and Social Research Council's framework for research ethics (ESRC, 2015).

This method led to an initial sample of 105 young participants with CP, which reflects our efforts to gather a minimal sample size, suitable for analyzing structural equation models (Wolf, Harrington, Clark, \& Miller, 2013). Later, three participants were removed from the dataset, because they were identified as multivariate outliers (see Section 2.4). The remaining 102 students (52 boys and 50 girls) presented a mean age of 18.05 years $(\mathrm{SD}=3.88)$. All students come from the prefecture of Thessaloniki (Central Macedonia, Greece), which has approximately $1,110,000$ inhabitants. Its predominantly urban population is mostly gathered in the city center and in city clusters (Regional Statistics Team, 2013). Most of the participants (84.3\%) were physically active only at their school's adapted Physical Education, which took place two to three times a week. The rest of the participants undertake additional adapted sports in their free time.

\subsection{Procedure}

To study the self-regulation of students with $\mathrm{CP}$ we utilized the psychomotor task that was implemented in our previous studies (Varsamis \& Agaliotis, 2011, 2015). It is an individual test that offers an arrangement of multiple self-set goals and related motor performances. It is combined with questions about self-regulation. This task has a proven relevance to many dimensions of self-regulation and self-concept. Tasks like this have been often used to study motor performance, self-efficacy, self-regulation, and motivation in many sorts of samples (e.g., Locke \& Latham, 1990; Varsamis \& Agaliotis, 2011, 2015). Moreover, ball-throwing at targets is a widespread physical activity and part of many sports. In this context, setting own goals and determining throwing/shooting distance are the most common choices that are made available to the participants. The type of goal-setting ar- 
rangement used in our studies was firstly incorporated in early studies and interventions around aspiration level (see Heckhausen \& Heckhausen, 2018). Nonetheless, self-set goals combined with repeated efforts preserve an ecological validity due to their frequent use in physical education, games and sports. More to the point, goal-setting arrangements can be integrated in the microanalytical research paradigm (Cleary \& Zimmerman, 2004; Hadwin \& Webster, 2013).

The implemented task had the following structure: While sitting on his/her school chair or on his/her wheelchair, each student had to throw a soft plastic gymnastic ball with a diameter of $16 \mathrm{~cm}$, so that it rolls on the floor and enters a laying box through its side opening whose dimensions were $50 \mathrm{~cm}$ length and 30 $\mathrm{cm}$ height. After some preparatory throws, each one of the students decided on his/her preferred throwing distance (cf. Varsamis \& Agaliotis, 2011, 2015). Each student had at his/her disposal a total of 24 throws, divided in four sets of six throws. Before starting these throws, the student had to set a goal for the whole session, as well as for each set. Students received verbal feedback both after each throw (e.g., "Until now you have two successful throws out of four throws in total") and at the end of each set (e.g., "You have had three successful throws in this set, whereas your goal was four successful throws").

This task coincides with a criterion-referenced testing. It was originally designed a) to include as many students as possible, without hurting its quality, and b) to allow students to influence the task's difficulty. More, instead of evaluating aspects of self-observation, students were given feedback after each throw and set. Thus, all participants worked under an extensive, really supportive, goal-attaining feedback (Sharif et al., 2015; Locke \& Latham, 2002).

\subsection{Measurements}

Measurements were carried out during the calendar years 2016 and 2017. The main characteristics of Cerebral Palsy were reported by the parents based on official medical reports. The students' weekly physical and sports activity emerged from the statements of the parents and from the school curriculum. The current cognitive functioning of the students was documented by the psychologist of each school unit, who classified students according to the b117 code of the ICF-CY (WHO, 2007) and gave indicative measurement units for the Intellectual Quotient as follows: (0) none/negligible difficulties (>86), (1) mild difficulties (71 85), and (2) moderate difficulties (55 - 70, see also Cheong \& Johnston, 2013). Gross motor functions were assessed by the institutions' physiotherapist or that of the family, based on the Gross Motor Function Classification System-Expanded \& Revised (GMFCS_E \& R, Palisano et al., 2008). Hand functions were estimated by the Adapted Physical Education teacher of each school, by using the Manual Ability Classification System (MACS, Eliasson et al., 2006). All psychologists, physiotherapists and Adapted Physical Education teachers knew each participant for at least one academic year.

According to our theoretical positions, it would be appropriate to assess the 
general self-efficacy as a personality factor that may affect actions in the field. The conceptually closest code of the ICF-CY is found in Confidence (b1266), which is part of temperament and personality functions (b126). However, since we are not aware of a relevant classification system, we turned to the assessment of the self-reported General Self-Efficacy (cf. Glynou, Schwarzer, \& Jerusalem, 1994). Specifically, we used only the part of the questionnaire, which is related to coping self-efficacy (Zhou, 2016), because a) it was considered to be more relevant to tasks like our own, as compared to the action self-efficacy (Evers, Klusmann, Schwarzer, \& Heuser, 2011), and b) a special effort was made, to keep the duration of the test as short as possible, due to the restrictions of people with $\mathrm{CP}$ in concentration and working memory (Jenks, de Moor, \& van Lieshout, 2009; Shank, Kaufman, Leffard, \& Warschausky, 2010). While assessing general self-efficacy, the originally used four point Likert scale was modified to a five point Likert scale ranging from "not at all" to "very much", since this is-to our knowledge-very comprehensible by our students (Varsamis \& Agaliotis, 2011).

Our previously implemented test (Varsamis \& Agaliotis, 2011, 2015) was now enriched with newly formulated-and in some cases, with slightly reformulated-questions extending on the facets of self-efficacy and self-evaluation (cf. Cleary et al., 2012). Thus, it was decided to employ the following classes of variables: 1) Distance from target, which was stable across all sets and throws. 2) Goal-setting, i.e., initial goal ("Which is the goal you want to achieve?"), followed by the four goals set by the students in each set. 3) Motor performances achieved by the students at the end of each set. 4) Task-specific self-efficacy based on one question ("How well do you believe you are going to achieve in this task?"). 5) Goal-specific self-efficacy derived from one question ("How confident do you feel about doing what it is needed to achieve your goals?"). 6) Self-evaluation related to goal attainment, based on one question ("How well did you do, while you were trying to attain your goals?"). 7) Self-satisfaction, derived from one question ("How satisfied do you feel from your achievements in this task?"). Except goals, throws and distance, all other answers were rated on the basis of a seven point Likert scale ranging from "not at all" to "very much". Adapted physical education teachers conducted the test and gathered the data on the above-mentioned parameters.

The derivative variables used in our previous studies (Varsamis \& Agaliotis, 2011 , 2015) reflect the work made in some additional aspects of self-regulation, such as task strategies, strategic planning, and adaptive actions. Although studying these derivative variables proved to be useful for the understanding of self-regulation, they are not included in the present study because they usually connect different time phases and/or different self-regulation levels. Their inclusion would pose a problem for the required independence of the levels in the intended statistical model. Moreover, achieving the highest possible percentage of explained variance for self-evaluation goes beyond the objectives of this study. 


\subsection{Statistics}

As far as measurement quality is concerned, Cronbach's Alpha was calculated to assess the internal consistency. Furthermore, test-retest reliability was estimated via the intra-class correlation coefficient. This examination was based on our current research data and it was studied in a subsample of six boys and eight girls $(\mathrm{N}=14)$ with a mean age of 20.0 years $(\mathrm{SD}=4.39)$. This group was tracked for 6 weeks, whilst no self-regulation interventions took place. Multivariate outliers were identified through the proposed procedure of the statistical program SPSS (IBM Corp., 2011).

All factor analyses and structural equations were performed using the statistical program LISREL (Jöreskog \& Sörbom, 2017). These statistical procedures can depict multiple relationships among variables and give measurements of good data fit to the proposed model (Schermelleh-Engel, Moosbrugger, \& Müller, 2003). We focused on two theory-driven Multiple Indicators and Multiple Causes (MIMIC) models. Among the advantages of this approach counts the display of complex compositions of factors affecting the function of a particular area of action. Also, it is made possible to clarify the effects exerted by formative components on the model's reflective indicators, via predetermined latent variables (e.g., Posey, Roberts, Lowry, \& Bennett, 2015).

\section{Results}

Table 1 shows the main characteristics of the students based on the functions of muscle tone, the body parts affected, the concomitant epilepsy declared, and the identified autism prevalence. As far as muscle tone is concerned, two approaches were used, both based upon the classification tree proposed by the Surveillance of Cerebral Palsy in Europe (2000). Also, the classification of body parts affected was added, because it is still used in several countries. Generally, the distribution of CP subtypes found is to a certain extent similar to the percentages observed in Europe. Still, the inclusion criteria applied in the present investigation, in particular the ability of people to handle the ball with both hands, created some differentiations from the expected European $\mathrm{CP}$ quota. For example, Table 3 suggests that boys and girls may differ in the selected disability characteristics. Table 2 lists the basic functional characteristics of the sample. Overall, it seems that in each functional domain prevail students with minor and moderate dysfunctions. However, the percentage of students having only negligible difficulties in all three domains is just $25.5 \%$. At this point it is useful to note that separate analyses for any subgroup by far exceed the purpose of the present study.

The five questions of the factor coping self-efficacy, which stems from the questionnaire General Self-Efficacy, exhibited an acceptable internal consistency (Cronbach's Alpha $=.75)$ and an excellent test-retest reliability $($ ICC $=.92, p$ $<.001)$. The structure of this factor was adequately confirmed $\left(\chi^{2}(5)=7.818, p\right.$ $=.167, \chi^{2} / \mathrm{df}=1.564, \mathrm{NNFI}=.946, \mathrm{CFI}=.970, \mathrm{AGFI}=.910, \mathrm{SRMR}=.048$ and RMSEA $=.074\left(\mathrm{CI}_{90 \%}: .000-.169\right)$. All the items loaded statistically significantly 
Table 1. Frequencies and percentages of core Cerebral Palsy characteristics.

\begin{tabular}{|c|c|c|}
\hline & $\mathrm{N}$ & $\%$ \\
\hline \multicolumn{3}{|l|}{ Muscle tone (first order categories) } \\
\hline Spastic bilateral CP & 39 & 38.2 \\
\hline Spastic unilateral CP & 17 & 16.7 \\
\hline Dystonic CP & 16 & 15.7 \\
\hline Choreo-athetotic CP & 8 & 7.8 \\
\hline Ataxic CP & 6 & 5.9 \\
\hline Mixed muscle tone $\mathrm{CP}$ & 9 & 8.8 \\
\hline Non-classifiable CP & 7 & 6.9 \\
\hline \multicolumn{3}{|l|}{ Muscle tone (second order categories) } \\
\hline Spastic CP & 56 & 54.9 \\
\hline Dyskinetic CP & 24 & 23.5 \\
\hline Hypotonic CP & 13 & 12.8 \\
\hline Mixed CP & 9 & 8.8 \\
\hline \multicolumn{3}{|l|}{ Number of body parts affected } \\
\hline Tetraplegia & 47 & 46.1 \\
\hline Diplegia & 28 & 27.4 \\
\hline Hemiplegia & 17 & 16.7 \\
\hline Triplegia & 3 & 2.9 \\
\hline Non-classifiable & 7 & 6.9 \\
\hline \multicolumn{3}{|l|}{ Epilepsy } \\
\hline Current seizures & 4 & 3.9 \\
\hline \multicolumn{3}{|l|}{ Autism } \\
\hline Autism Spectrum Disorder & 1 & 1.0 \\
\hline
\end{tabular}

Table 2. Frequencies and percentages of core functional characteristics.

\begin{tabular}{lcc}
\hline & $\mathrm{N}$ & $\%$ \\
\hline Gross motor functions (GMFCS) & 58 & 56.9 \\
1 Walks without restrictions & 19 & 18.6 \\
2 Limitations walking outdoors & 14 & 13.8 \\
3 Walks with assistive devices & 8 & 7.8 \\
4 Self-mobility with limitations & 3 & 2.9 \\
5 Self-mobility severely limited & & \\
Manual ability functions (MACS) & 39 & 38.2 \\
1 Handles objects easily and independently & 35 & 34.3 \\
2 Handles objects with reduced quality/speed & 23 & 22.6 \\
3 Handles objects with difficulty; needs help & 5 & 4.9 \\
4 Handles easily managed objects; needs help & & \\
Cognitive functions (b117, ICF-CY) & 50 & 49.0 \\
0 No or negligible problems & 34 & 33.4 \\
1 Mild or slight problems & 18 & 17.6 \\
2 Moderate problems & & \\
\hline
\end{tabular}


on the factor; errors among the items were uncorrelated.

With regard to the goal-performance arrangement, exhaustive descriptive, exploratory and confirmatory factor analyses, these revealed that students used the first two attempts, i.e., sets, to harmonize their goals with their performance. So, they were engaged in a gradual reduction of their first two goals, in relation to their initial goal. At the same time, students achieved their highest performance in the third and fourth attempts. However, these adaptive actions could not fit in a structural equation model, because their indices were poor, or the tested solutions were statistically improper (Kyriazos, 2018). The only structure that was confirmed, comprised a factor with two goals and a factor with two performances, all coming from the sets three and four $\left(\chi^{2}(4)=4.733, p=.316, \chi^{2} / \mathrm{df}=\right.$ $1.933, \mathrm{NNFI}=.971, \mathrm{CFI}=.989, \mathrm{AGFI}=.934, \mathrm{SRMR}=.046$, and $\mathrm{RMSEA}=.042$ $\left(\mathrm{CI}_{90 \%}: 000\right.$ - .161). In this model, the initial goal served as a covariate; measurement errors of the fourth goal and of the initial goal were allowed to be correlated.

Although questions devoted to the assessment of self-directed beliefs are usually complementary to each other (Cleary, Durning, \& Artino, 2016), the good fit of two theory-driven factors was here confirmed. Specifically, questions four and five make up efficacy beliefs, while questions six and seven describe self-reflections $\left(\chi^{2}(1)=1.082, p=.298, \chi^{2} / \mathrm{df}=1.082, \mathrm{NNFI}=.990, \mathrm{CFI}=.998\right.$, AGFI $=.948$, SRMR $=.021$, and RMSEA $=.028\left(\mathrm{CI}_{90 \%}: .000-.266\right)$.

Internal consistency and test-retest reliability were calculated for all the variables involved in the psychomotor task. The first one was acceptable (Cronbach's Alpha $=.71)$ and the second one was excellent $($ ICC $=.90, p<.001)$. Throwing distance did not show widespread significant correlations with other variables and it was thus not included in any of the above-mentioned structures. Test-retest reliability of the throwing distance was good (ICC $=.85, p<.001$ ).

The relationships between single research variables are displayed in Table 3. Pearson's coefficients demonstrated the correlations observed among the standardized values (Z-scores) of the variables. Relationships indicated in this table served as a basis for the models developed here. As noted earlier, throwing distance and the initial goal were not heavily associated with other variables of the psychomotor task; hence, they were further conceived as formative parameters. Any attempts to place all goal-setting variables in a formative role, led to improper statistical models. Thus, initial and ongoing goals seemed to be hierarchical in our MIMIC models. In other words, personal goals are both formative and reflective (for this discussion, see Locke \& Latham, 2002).

Model 1 represents the first modified MIMIC viable solution (see Figure 1), which was reached by analyzing self-regulation variables, both as to their cyclical nature, as well as to their conceptual pertinence. Most indicators of this model were good (Table 4). Gross motor functions (GMFCS) could be employed as a significant formative covariate. Despite their significant correlations, age, gender, and physical activity (cf. Table 3 ) showed only negligible causal influences on 
Table 3. Zero-order correlations among study variables

\begin{tabular}{|c|c|c|c|c|c|c|c|c|c|c|c|c|c|c|c|c|}
\hline & Gender & Age & GMFCS & MACS & b117 & CGSE & $\mathrm{PE} / \mathrm{A}$ & $\mathrm{TD}$ & IG & EB1 & $\mathrm{EB} 2$ & GS3 & GS4 & MP3 & MP4 & SR1 \\
\hline Age & -.17 & & & & & & & & & & & & & & & \\
\hline GMFCS & $.22^{*}$ & $.26^{\star \star}$ & & & & & & & & & & & & & & \\
\hline MACS & $.31^{* *}$ & .09 & $.64^{* *}$ & & & & & & & & & & & & & \\
\hline b117 & $.28^{\star *}$ & $-.36^{\star *}$ & .05 & $.32^{\star *}$ & & & & & & & & & & & & \\
\hline CGSE & -.17 & -.16 & $-.34^{* *}$ & $-.20^{*}$ & .02 & & & & & & & & & & & \\
\hline $\mathrm{PE} / \mathrm{A}$ & -.09 & -.14 & -.12 & .02 & -.03 & $.26^{\star *}$ & & & & & & & & & & \\
\hline $\mathrm{TD}$ & -.15 & -.15 & $-.36^{\star *}$ & $-.34^{\star \star}$ & -.06 & .11 & .14 & & & & & & & & & \\
\hline IG & .04 & -.12 & -.05 & -.05 & .19 & .14 & -.04 & .11 & & & & & & & & \\
\hline EB1 & .01 & .10 & .04 & .07 & $.29^{* *}$ & $.24^{*}$ & .07 & -.16 & $.27^{* *}$ & & & & & & & \\
\hline EB2 & -.05 & -.09 & -.14 & -.07 & $.41^{\star *}$ & .17 & .09 & .09 & $.20^{*}$ & $.29^{\star *}$ & & & & & & \\
\hline GS3 & -.15 & .02 & -.09 & $-.27^{\star \star}$ & -.10 & .06 & -.07 & .05 & .16 & -.01 & .16 & & & & & \\
\hline GS4 & -.12 & -.07 & -.06 & -.19 & -.17 & .04 & -.17 & -.01 & $.23^{*}$ & -.01 & .06 & $.36^{\star *}$ & & & & \\
\hline MP3 & -.15 & -.07 & $-.27^{\star *}$ & $-.30^{\star *}$ & -.02 & -.05 & -.18 & -.00 & -.04 & -.02 & .08 & $.20^{*}$ & $.44^{\star *}$ & & & \\
\hline MP4 & $-.20^{*}$ & .01 & -.18 & $-.29^{\star *}$ & -.12 & .10 & -.14 & -.05 & -.05 & .01 & -.00 & $.27^{\star *}$ & $.31^{* *}$ & $.44^{* *}$ & & \\
\hline SR1 & -.09 & -.11 & -.09 & -.02 & $.25^{\star}$ & $.30^{\star *}$ & .19 & $-.21^{\star}$ & -.02 & $.23^{*}$ & $.37^{\star *}$ & $.23^{*}$ & .04 & .10 & $.21^{\star}$ & \\
\hline SR2 & $-.25^{\star}$ & -.13 & $-.27^{\star \star}$ & $-.25^{\star}$ & .18 & $.44^{\star \star}$ & -.01 & -.12 & .00 & .12 & $.30^{* *}$ & $.23^{*}$ & .01 & .15 & $.29^{* *}$ & $.45^{\star *}$ \\
\hline
\end{tabular}

Note. GMFCS: Gross motor functions; MACS: Hand functions; b117: Cognitive functions; CGSE: Coping General Self-Efficacy; PE/A: Physical Education/Activity; TD: Throwing Distance; IG: Initial Goal; EB: Efficacy-Beliefs; GS: Goal-Setting; MP: Motor Performance; SR: Self-Reflection.

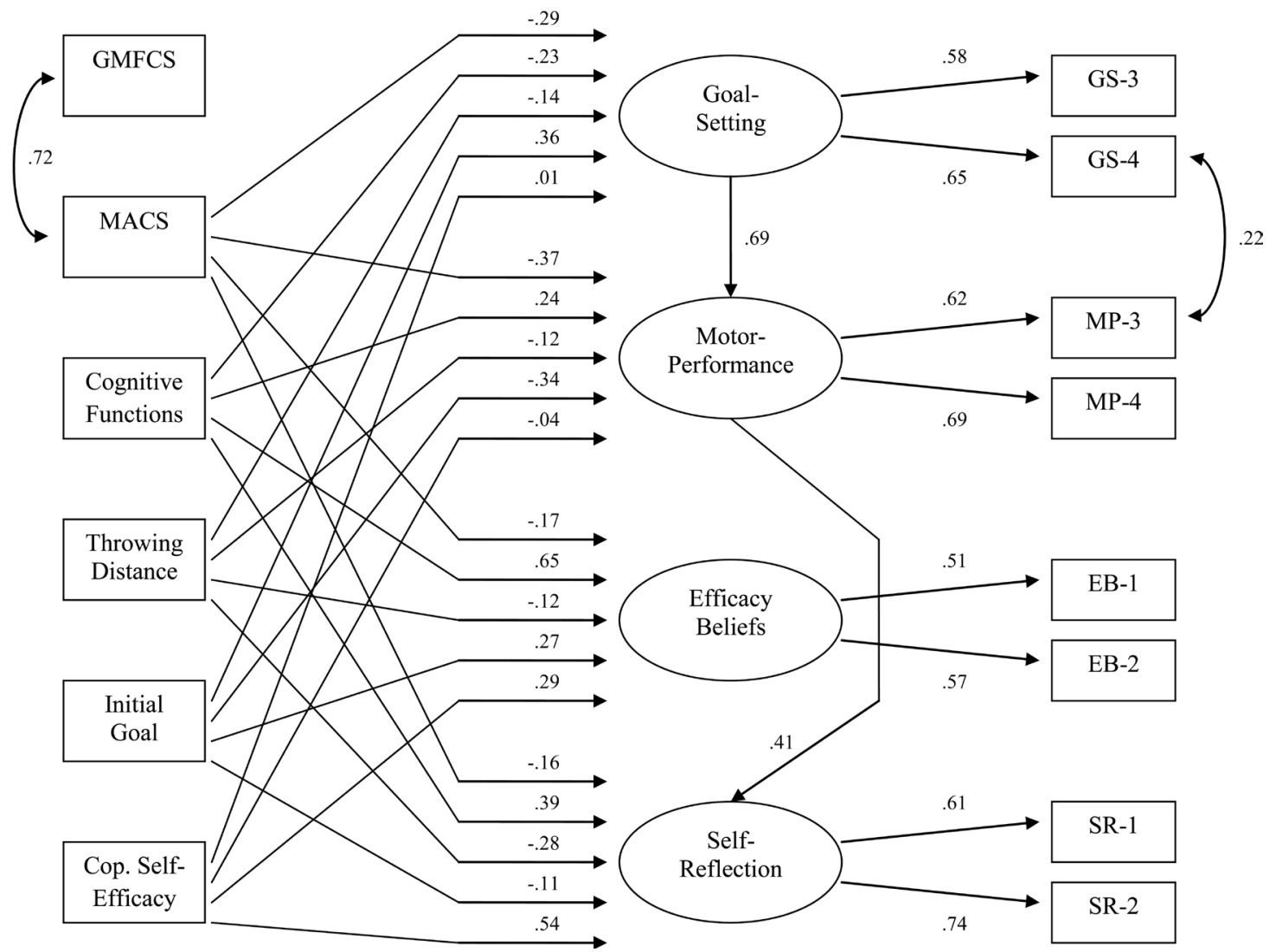

Figure 1. Modified Model 1. 
the latent variables and thus, they could not be included in this model. As expected, low hand functions affect negatively goal-setting, motor performance, and self-reflections. It emerged that cognitive dysfunctions and high coping self-efficacy significantly contribute to efficacy beliefs and self-reflections. Furthermore, self-reflections were notably influenced by all formative factors, except by the initial goal. A high initial goal is predictive for setting high ongoing goals and for high efficacy beliefs. Even if the standardized value describing the negative influence of the initial goal on motor performance is rather high (-.34), its unstandardized value does not meet statistical significance; LISREL does not produce standard error estimates, i.e., significance levels, of the completely standardized solution.

The relationships among the latent factors displayed a great influence of goal-setting on motor performance, which in turn significantly forges self-reflections. Moreover, covariances between efficacy beliefs and self-reflections (.42), and between goal-setting and self-reflections (.24), were statistically significant. However, covariances between efficacy beliefs and goal-setting, as well as between efficacy beliefs and motor-performance were trivial. In this model, predicted variance $\left(\mathrm{R}^{2}\right)$ was .27 for Goal-Setting, .62 for Motor-Performance, .66 for Efficacy Beliefs, and .72 for Self-Reflections.

In our second MIMIC model, a conceptual grouping of self-regulation indicators, forming goal-motor attainments and competence reflections, was initiated (see Figure 2). Most indicators of Model 2 were acceptable (Table 4). In this conceivement, the initial goal could not affect any of the latent variables. Also, gross motor functions could not be involved. All other formative variables influenced competence reflections significantly, while the goal-motor construct

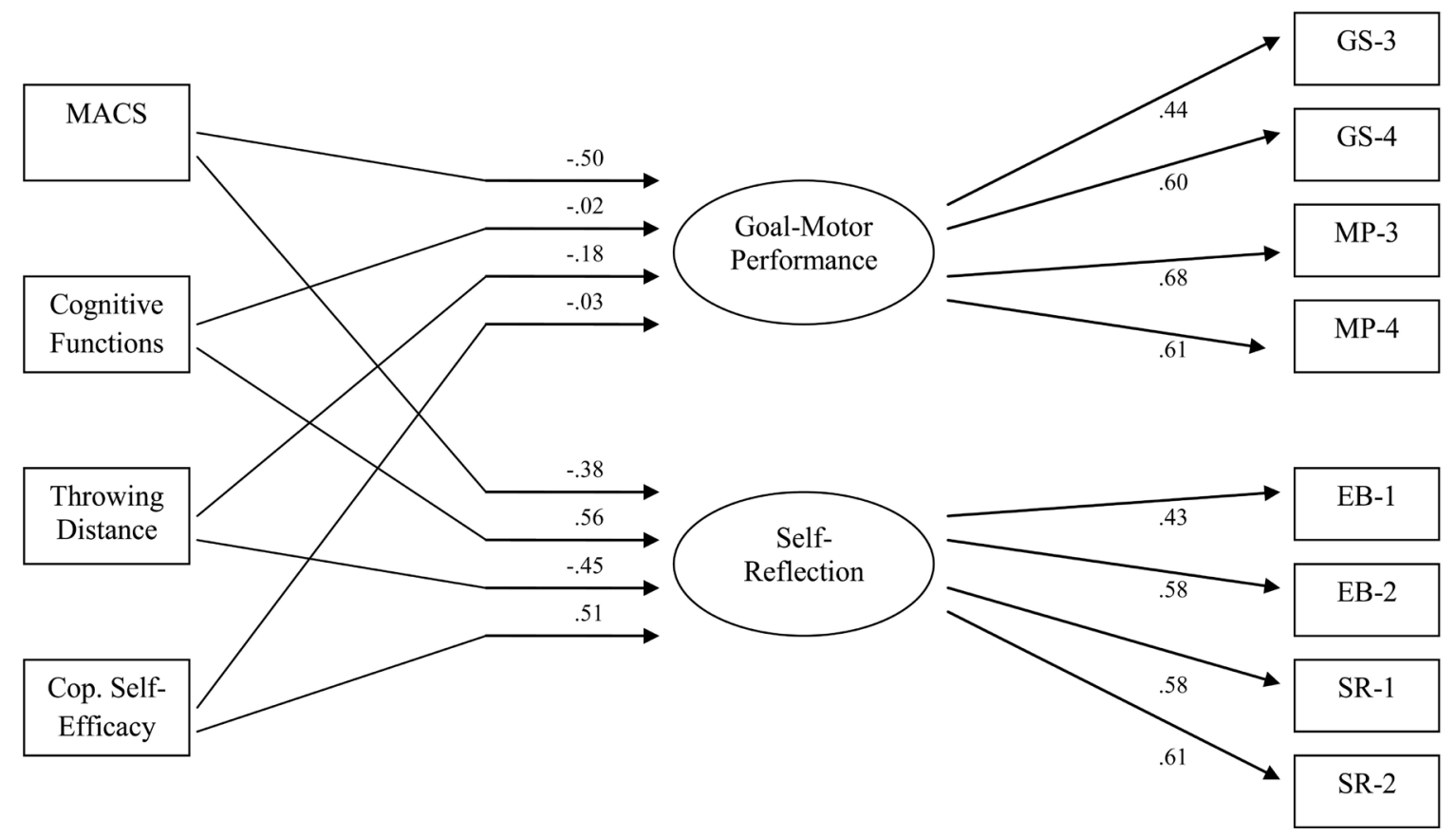

Figure 2. Modified Model 2. 
Table 4. Goodness of fit indices of the MIMIC models.

\begin{tabular}{ccccccccccc}
\hline & $\chi^{2}$ & $\mathrm{df}$ & $p$ & $\chi^{2} / \mathrm{df}$ & NNFI & CFI & AGFI & SRMR & RMSEA & CI $_{90 \%}$ \\
\hline Model 1 & 51.10 & 44 & .22 & 1.16 & .95 & .98 & .86 & .06 & .04 & $.00-.08$ \\
Model 2 & 60.58 & 43 & .04 & 1.40 & .87 & .92 & .84 & .08 & .06 & $.02-.10$ \\
\hline
\end{tabular}

was significantly affected only by hand functions. The covariance between the two latent factors was statistically insignificant. The difference between the two models in terms of the CFI index is large (cf. Byrne, 2008). Thus, Model 1 should be preferred over Model 2.

\section{Discussion}

The main purpose of our study was to confirm levels of motivation and self-regulation in students with CP by considering the simultaneous influence of selected disability and personal characteristics. In the first theory-driven MIMIC model, four levels of functioning were crystallized, namely, goal-setting, motor performance, efficacy beliefs, and self-reflections. As expected, these levels receive multiple significant influences by disability variables such as hand mobility. Although in the present psychomotor task, trunk control was certainly needed, students' gross motor functions were not able to demonstrate a direct effect. This result replicates previous findings (Varsamis \& Agaliotis, 2015). In the present study, throwing distance and initial goal-setting could only hold well in the role of personal characteristics, suggesting that the latter may be rather stable expressions of one's personality (cf. Locke \& Latham, 2013). Coping self-efficacy was a great predictor of both the cognitive and the evaluative reflective indicators.

Although cognitive functions showed expected correlations with the variables of age, hand functions and goal-setting, they were drafted in the model having a negative statistical role. That is, the lower the cognitive functions of the $\mathrm{CP}$ students, the higher the motor performance, the efficacy beliefs, and the self-reflection in this task (cf. Varsamis \& Agaliotis, 2011). At this point, it is useful to underscore that low goal attainment and unrealistically positive self-evaluations can be dysfunctional for personal and social thriving (Schuengel et al., 2006).

Initial goals did further justify their role as a trait-like, even perhaps a subconscious, formative factor (cf. Latham, 2016), as they were uncorrelated to motor performance and to the affective level of the self-regulation. Initial goals and throwing distance may be viewed as an index of task difficulty posed by each student. Consequently, when it comes to interventions, it seems more viable to start with the ongoing goals, rather than the initial ones.

Relationships among the latent variables in Model 1 are consistent with former theoretical implications. However, the expected role of the task and goal specific self-efficacy in goal-setting and in motor performance was not confirmed, thus challenging the postulated circularity of self-regulation phases. Classic path analysis should probably be preferred over MIMIC modeling, if one 
aims at examining the cyclicity of self-regulation. Nevertheless, this problem may be due to the way self-efficacy was assessed; it was greatly anchored to throwing distance and to the initial goal. This issue is then coupled with the phenomenon of dramatically reducing the initial goal. Besides, lose relationships among the above-mentioned variables could mean that the task was rather complex for students with CP (cf. Locke \& Latham, 2002). According to a further explanation, students with $\mathrm{CP}$ were pretty much influenced by their past negative experiences (Bandura \& Locke, 2003), which may result to fragmented self-functioning (Hadwin \& Webster, 2013).

In Model 2, where the four levels of self-regulation were merged in two, a rather lower structural quality was achieved. In this model, the initial goal did not play a statistically significant role; it could not be included. Furthermore, the relationship between the goal-motor level and the cognitive-affective level was not significant. Model 2 demonstrated that several aspects of self-regulation may be strongly correlated, but it failed to prove that the two self-regulation levels were notably interflected. Taken altogether, Model 1 is to be preferred, because it exhibits both theoretical and empirical robustness.

Finally, the remaining available personal factors, namely, weekly physical activity, age and gender, were unable to join any of the two models, suggesting on the one hand that they do not play a major role in the microanalytical examination of psychomotor activities, and on the other hand that their role is probably reduced in the light of disability and personal factors (Varsamis \& Papadopoulos, 2014). A further striking finding of the present research was that CP students made major corrections of their goals, despite the fact that they practiced several pilot throws before the main testing. Unfortunately, this adaptive strategy could not be captured by the confirmatory factor analysis as an independent phase of self-regulation. In future studies, it could be useful to grant more sets in order to document this adaptation strategy and to further study its role in self-regulation.

Since people with $\mathrm{CP}$ often have difficulties in articulating and verbalizing, as well as in maintaining attention for long periods of time, we implemented only a few questions to investigate their self-regulation in this psychomotor task. So, we focused on two central levels, namely, efficacy beliefs and self-evaluation. However, this led to a rather performance-oriented view of self-regulation, whereas qualitative aspects of the learning process were not actually included. Further limitations of the present study refer to the sampling method and the participants' selection criteria, which certainly influenced the representativeness of the sample. Also, the classification of CP relied exclusively on the data given by parents, professionals and teachers. Despite of these imperfections, the present study provides a reliable model for understanding levels of self-regulation of students with $\mathrm{CP}$, that is to say, a special population, which is difficult to concentrate in large numbers.

Besides providing more throwing sets, future research needs to extend into 
learning goals as well as into tasks which vary in complexity. The longitudinal examination of the proposed model may reveal further causal effects. Undoubtedly, the involvement of further critical personal characteristics, such as responsibility for learning and mastery motivation, can add to the explanatory power of our model. Finally, the use of objective physical and cognitive measurements usually leads to a precise assessment of disability features. This may give more accurate psychometric properties to the statistical models.

\section{Conclusion}

In conclusion, results of the present research add valuable information on studying motivation and self-regulation in the light of congenital Cerebral Palsy. Namely, it has been revealed that specific disability and personality factors significantly intervene with goal pursuits. Beyond that, it was proved constructive to verify the complex relationships between higher-level, i.e., formative, factors and situative, i.e., reflective, indicators. A striking result of this effort was that goal notions may be hierarchically organized, as they were found in both formative and reflective facets of the qualified statistical model. Taking into account that a goal adaptation strategy also emerged, self-regulation appeared to be a multifaceted guiding entity, which deserves further investigation.

\section{Conflicts of Interest}

The authors declare no conflicts of interest regarding the publication of this paper.

\section{References}

Bandura, A., \& Locke, E. A. (2003). Negative Self-Efficacy and Goal Effects Revisited. The Journal of Applied Psychology, 88, 87-99. https://doi.org/10.1037/0021-9010.88.1.87

Bjornson, K. F., Zhou, C., Stevenson, R., \& Christakis, D. A. (2013). Capacity to Participation in Cerebral Palsy: Evidence of an Indirect Path via Performance. Archives of Physical Medicine and Rehabilitation, 94, 2365-2372. https://doi.org/10.1016/j.apmr.2013.06.020

Blair, E., \& Cans, C. (2018). The Definition of Cerebral Palsy. In C. P. Panteliadis (Ed.), Cerebral Palsy: A Multidisciplinary Approach (pp. 13-17). Cham: Springer International Publishing AG. https://doi.org/10.1007/978-3-319-67858-0_2

Blair, E., Cans, C., \& Sellier, E. (2018). Epidemiology of the Cerebral Palsies. In C. P. Panteliadis (Ed.), Cerebral Palsy: A Multidisciplinary Approach (pp. 19-28). Cham: Springer International Publishing AG. https://doi.org/10.1007/978-3-319-67858-0_3

Bottcher, L. (2010). Children with Spastic Cerebral Palsy, Their Cognitive Functioning, and Social Participation: A Review. Child Neuropsychology, 16, 209-228. https://doi.org/10.1080/09297040903559630

Byrne, B. (2008). Testing for Multigroup Equivalence of a Measuring Instrument: A Walk through the Process. Psicothema, 20, 872-882.

Cheong, S. K., \& Johnston, L. M. (2013). Systematic Review of Self-Concept Measures for Primary School Aged Children with Cerebral Palsy. Research in Developmental Disabilities, 34, 3566-3575. https://doi.org/10.1016/j.ridd.2013.07.023 
Christensen, D., Van Naarden Braun, K., Doernberg, N. S., Maenner, M. J., Arneson, C. L., Durkin, M. S., Yeargin-Allsopp, M. et al. (2014). Prevalence of Cerebral Palsy, Co-Occurring Autism Spectrum Disorders, and Motor Functioning-Autism and Developmental Disabilities Monitoring Network, USA, 2008. Developmental Medicine \& Child Neurology, 56, 59-65. https://doi.org/10.1111/dmcn.12268

Cleary, T. J., \& Platten, P. (2013). Examining the Correspondence between Self-Regulated Learning and Academic Achievement: A Case Study Analysis. Education Research International, 2013, Article ID: 272560. https://doi.org/10.1155/2013/272560

Cleary, T. J., \& Zimmerman, B. J. (2004). Self-Regulation Empowerment Program: A School-Based Program to Enhance Self-Regulated and Self-Motivated Cycles of Student Learning. Psychology in the Schools, 41, 537-550. https://doi.org/10.1002/pits.10177

Cleary, T. J., Callan, G. L., \& Zimmerman, B. J. (2012). Assessing Self-Regulation as a Cyclical, Context-Specific Phenomenon: Overview and Analysis of SRL Microanalytic Protocols. Education Research International, 2012, Article ID: 428639.

https://doi.org/10.1155/2012/428639

Cleary, T. J., Durning, S. J., \& Artino, A. R. (2016). Microanalytic Assessment of Self-Regulated Learning during Clinical Reasoning Tasks. Academic Medicine, 91, 1516-1521. https://doi.org/10.1097/ACM.0000000000001228

Davis, W. E., \& Burton, A. W. (1991). Ecological Task Analysis: Translating Movement Behavior Theory into Practice. Adapted Physical Activity Quarterly, 8, 154-177. https://doi.org/10.1123/apaq.8.2.154

Eliasson, A., Krumlinde-Sundholm, L., Rösblad, B., Beckung, E., Arner, M., Öhrvall, A., \& Rosenbaum, P. (2006). The Manual Ability Classification System (MACS) for Children with Cerebral Palsy: Scale Development and Evidence of Validity and Reliability. Developmental Medicine \& Child Neurology, 48, 549-554.

https://doi.org/10.1017/S0012162206001162

ESRC (2015). Framework for Research Ethics.

http://www.esrc.ac.uk/files/funding/guidance-for-applicants/esrc-framework-for-resea rch-ethics-2015

EURO-PERISTAT (2008). European Perinatal Health Report. Data from 2004. http://www.europeristat.com

Evers, A., Klusmann, V., Schwarzer, R., \& Heuser, I. (2011). Adherence to Physical and Mental Activity Interventions: Coping Plans as a Mediator and Prior Adherence as a Moderator. British Journal of Health Psychology, 17, 477-491. https://doi.org/10.1111/j.2044-8287.2011.02049.x

Glynou, E., Schwarzer, R., \& Jerusalem, M. (1994). Greek Adaptation of the General Self-Efficacy Scale. http://userpage.fu-berlin.de/ health/greek.htm

Gofer-Levi, M., Silberg, T., Brezner, A., \& Vakil, E. (2013). Deficit in Implicit Motor Sequence Learning among Children and Adolescents with Spastic Cerebral Palsy. Research in Developmental Disabilities, 34, 3672-3678.

https://doi.org/10.1016/j.ridd.2013.07.029

Graham, H. K., Rosenbaum, P., Paneth, N., Dan, B., Lin, J., Damiano, D. L., Lieber, R. L. et al. (2016). Cerebral Palsy. Nature Reviews Disease Primers, 2, Article No. 15082. https://doi.org/10.1038/nrdp.2015.82

Hadwin, A. F., \& Webster, E. A. (2013). Calibration in Goal Setting: Examining the Nature of Judgments of Confidence. Learning and Instruction, 24, 37-47.

https://doi.org/10.1016/j.learninstruc.2012.10.001

Heckhausen, J., \& Heckhausen, H. (2018). Motivation and Action. New York: Springer. https://doi.org/10.1007/978-3-319-65094-4 
Hidecker, M. J. C., Paneth, N., Rosenbaum, P. L., Kent, R. D., Lillie, J., Eulenberg, J. B., Chester, K., Johnson, B., Michalsen, L., Evatt, M., \& Taylor, K. (2011). Developing and Validating the Communication Function Classification System (CFCS) for Individuals with Cerebral Palsy. Developmental Medicine and Child Neurology, 53, 704-710. https://doi.org/10.1111/j.1469-8749.2011.03996.x

Huang, H.-H. (2018). Perspectives on Early Power Mobility Training, Motivation, and Social Participation in Young Children with Motor Disabilities. Frontiers in Psychology, 8, 2330. https://doi.org/10.3389/fpsyg.2017.02330

Hutzler, Y. (2007). A Systematic Ecological Model for Adapting Physical Activities: Theoretical Foundations and Practical Examples. Adapted Physical Activity Quarterly, 24, 287-304. https://doi.org/10.1123/apaq.24.4.287

IBM Corp. (2011). IBM SPSS Statistics for Windows, Version 20.0. Armonk, NY: IBM Corp.

Jenks, K. M., De Moor, J., \& Van Lieshout, E. C. (2009). Arithmetic Difficulties in Children with Cerebral Palsy Are Related to Executive Function and Working Memory. Journal of Child Psychology and Psychiatry, 50, 824-833. https://doi.org/10.1111/j.1469-7610.2008.02031.x

Jöreskog, K. G., \& Sörbom, D. (2017). LISREL 9.30: User's Reference Guide. Lincolnwood, IL: Scientific Software International.

Kyriazos, T. A. (2018). Applied Psychometrics: Sample Size and Sample Power Considerations in Factor Analysis (efa, CFA) and SEM in General. Psychology, 9, 2207-2230. https://doi.org/10.4236/psych.2018.98126

Laporta-Hoyos, O., Pannek, K., Ballester-Plané, J., Reid, L. B., Vázquez, É., Delgado, I., Pueyo, R. et al. (2017). White Matter Integrity in Dyskinetic Cerebral Palsy: Relationship with Intelligence Quotient and Executive Function. NeuroImage: Clinical, 15, 789-800. https://doi.org/10.1016/j.nicl.2017.05.005

Latham, G. (2016). Goal-Setting Theory: Causal Relationships, Mediators, and Moderators. https://doi.org/10.1093/acrefore/9780190236557.013.12 http://oxfordre.com/psychology/view/10.1093/acrefore/9780190236557.001.0001/acref ore-9780190236557-e-12

Locke, E. A., \& Latham, G. P. (1990). A Theory of Goal Setting \& Task Performance. Englewood Cliffs, NJ: Prentice-Hall, Inc.

Locke, E. A., \& Latham, G. P. (2002). Building a Practically Useful Theory of Goal Setting and Task Motivation. A 35-Year Odyssey. The American Psychologist, 57, 705-717. https://doi.org/10.1037/0003-066X.57.9.705

Locke, E. A., \& Latham, G. P. (2013). New Developments in Goal Setting and Task Performance. New York: Routledge. https://doi.org/10.4324/9780203082744

McDougall, J., Wright, V., \& Rosenbaum, P. (2010). The ICF Model of Functioning and Disability: Incorporating Quality of Life and Human Development. Developmental Neurorehabilitation, 13, 204-211. https://doi.org/10.3109/17518421003620525

Miller, L., Ziviani, J., \& Boyd, R. N. (2013). A Systematic Review of Clinimetric Properties of Measurements of Motivation for Children Aged 5-16 Years with a Physical Disability or Motor Delay. Physical \& Occupational Therapy in Pediatrics, 34, 90-111. https://doi.org/10.3109/01942638.2013.771720

Murayama, K., Matsumoto, M., Izuma, K., Sugiura, A., Ryan, R. M., Deci, E. L., \& Matsumoto, K. (2013). How Self-Determined Choice Facilitates Performance: A Key Role of the Ventromedial Prefrontal Cortex. Cerebral Cortex, 25, 1241-1251. https://doi.org/10.1093/cercor/bht317 
Newell, K. M., \& Jordan, K. (2007). Task Constrains and Movement Organization: A Common Language. In W. Davis, \& B. D. Broadhead (Eds.), Ecological Task Analysis and Movement (pp. 5-23). Champaign, IL: Human Kinetics.

Norwich, B. (2016). Conceptualizing Special Educational Needs Using a Biopsychosocial Model in England: The Prospects and Challenges of Using the International Classification of Functioning Framework. Frontiers in Education, 1, 1-29. https://doi.org/10.3389/feduc.2016.00005

Palinkas, L. A., Horwitz, S. M., Green, C. A., Wisdom, J. P., Duan, N., \& Hoagwood, K. (2015). Purposeful Sampling for Qualitative Data Collection and Analysis in Mixed Method Implementation Research. Administration and Policy in Mental Health, 42, 533-544. https://doi.org/10.1007/s10488-013-0528-y

Palisano, R. J., Chiarello, L. A., King, G. A., Novak, I., Stoner, T., \& Fiss, A. (2011). Participation-Based Therapy for Children with Physical Disabilities. Disability and Rehabilitation, 34, 1041-1052. https://doi.org/10.3109/09638288.2011.628740

Palisano, R. J., Kang, L., Chiarello, L. A., Orlin, M., Oeffinger, D., \& Maggs, J. (2009). Social and Community Participation of Children and Youth with Cerebral Palsy Is Associated with Age and Gross Motor Function Classification. Physical Therapy, 89, 1304-1314. https://doi.org/10.2522/ptj.20090162

Palisano, R. J., Rosenbaum, P., Bartlett, D., \& Livingston, M. H. (2008), Content Validity of the Expanded and Revised Gross Motor Function Classification System. Developmental Medicine \& Child Neurology, 50, 744-750. https://doi.org/10.1111/j.1469-8749.2008.03089.x

Patton, M. Q. (2015). Sampling, Qualitative (Purposeful). The Blackwell Encyclopedia of Sociology. https://doi.org/10.1002/9781405165518.wbeoss012.pub2

Paulson, A., \& Vargus-Adams, J. (2017). Overview of Four Functional Classification Systems Commonly Used in Cerebral Palsy. Children, 4, 30. https://doi.org/10.3390/children4040030

Posey, C., Roberts, T. L., Lowry, P. B., \& Bennett, R. J. (2015). Multiple Indicators and Multiple Causes (MIMIC) Models as a Mixed-Modeling Technique: A Tutorial and an Annotated Example. Communications of the Association for Information Systems, 36. http://aisel.aisnet.org/cais/vol36/iss1/11 https://doi.org/10.17705/1CAIS.03611

Regional Statistics Team (2013). Updated Urban-Rural Typology: Integration of NUTS 2010 and the Latest Population Grid. https://ec.europa.eu/eurostat/statistics-explained/pdfscache/24926.pdf

Rosenbaum, P., \& Stewart, D. (2004). The World Health Organization International Classification of Functioning Disability and Health: A Model to Guide Clinical Thinking, Practice and Research in the Field of Cerebral Palsy. Seminars in Pediatric Neurology, 11, 5-10. https://doi.org/10.1016/j.spen.2004.01.002

Rosenbaum, P., Paneth, N., Leviton, A., Goldstein, M., \& Bax, M. (2007). A Report: The Definition and Classification of Cerebral Palsy. Developmental Medicine \& Child Neurology, 49, 8-14.

Ryan, R. M., \& Deci, E. L. (2017). Self-Determination Theory. Basic Psychological Needs in Motivation, Development and Wellness. New York: Guilford Press.

Saebu, M., Sørensen, M., \& Halvari, H. (2013). Motivation for Physical Activity in Young adults with Physical Disabilities during a Rehabilitation Stay: A Longitudinal Test of Self-Determination Theory. Journal of Applied Social Psychology, 43, 612-625. https://doi.org/10.1111/j.1559-1816.2013.01042.x

Schermelleh-Engel, K., Moosbrugger, H., \& Müller, H. (2003). Evaluating the Fit of 
Structural Equation Models: Tests of Significance and Descriptive Goodness-of-Fit Measures. Methods of Psychological Research, 8, 23-74.

Schuengel, C., Voorman, J., Stolk, J., Dallmeijer, A., Vermeer, A., \& Becher, J. (2006). Self-Worth, Perceived Competence, and Behaviour Problems in Children with Cerebral Palsy. Disability and Rehabilitation, 28, 1251-1258. https://doi.org/10.1080/09638280600554652

Shank, L. K., Kaufman, J., Leffard, S., \& Warschausky, S. (2010). Inspection Time and Attention-Deficit/Hyperactivity Disorder Symptoms in Children with Cerebral Palsy. Rehabilitation Psychology, 55, 188-193. https://doi.org/10.1037/a0019601

Sharif, M. R., Hemayattalab, R., Sayyah, M., Hemayattalab, A., \& Bazazan, S. (2015). Effects of Physical and Mental Practice on Motor Learning in Individuals with Cerebral Palsy. Journal of Developmental and Physical Disabilities, 27, 479-487.

https://doi.org/10.1007/s10882-015-9432-6

Shikako-Thomas, K., Shevell, M., Schmitz, N., Lach, L., Law, M., Poulin, C., \& Majnemer, A. (2013). Determinants of Participation in Leisure Activities among Adolescents with Cerebral Palsy. Research in Developmental Disabilities, 34, 2621-2634. https://doi.org/10.1016/j.ridd.2013.05.013

Shogren, K. A., \& Wehmeyer, M. L. (2016). Relationship between Basic Psychological Needs, Motivation, Causal Action, and Self-Determination. Lawrence, KS: Kansas University Center on Developmental Disabilities. https://doi.org/10.1007/978-3-319-59066-0_5

Stavsky, M., Mor, O., Mastrolia, S. A., Greenbaum, S., Than, N. G., \& Erez, O. (2017). Cerebral Palsy-Trends in Epidemiology and Recent Development in Prenatal Mechanisms of Disease, Treatment, and Prevention. Frontiers in Pediatrics, 5, 21. https://doi.org/10.3389/fped.2017.00021

Surveillance of Cerebral Palsy in Europe (2000). Classification Tree for Sub-Types of Cerebral Palsy.

http://www.scpenetwork.eu/assets/SCPE-Tools/RT-Manual-tools/SCPE-CP-Classificati on-Tree.pdf

Surveillance of Cerebral Palsy in Europe (2002). Prevalence and Characteristics of Children with Cerebral Palsy in Europe. Surveillance of Cerebral Palsy in Europe. Developmental Medicine and Child Neurology, 44, 633-640. https://doi.org/10.1111/j.1469-8749.2002.tb00848.x

Van der Slot, W. M., Nieuwenhuijsen, C., van den Berg-Emons, R. J., Wensink-Boonstra, A. E., Stam, H. J., \& Roebroeck, M. E. (2010). Participation and Health-Related Quality of Life in Adults with Spastic Bilateral Cerebral Palsy and the Role of Self-Efficacy. Journal of Rehabilitation Medicine, 42, 528-535. https://doi.org/10.2340/16501977-0555

Varsamis, P. (2005). Förderung der Leistungserfahrung Körperbehinderter-Effekte individual-und gruppendidaktischer Formen. Motorik, 28, 196-203.

Varsamis, P., \& Agaliotis, I. (2011). Profiles of Self-Concept, Goal Orientation, and Self-Regulation in Students with Physical, Intellectual, and Multiple Disabilities: Implications for Instructional Support. Research in Developmental Disabilities, 32, 1548-1555. https://doi.org/10.1016/j.ridd.2011.01.054

Varsamis, P., \& Agaliotis, I. (2015). Relationships between Gross- and Fine Motor Functions, Cognitive Abilities, and Self-Regulatory Aspects of Students with Physical Disabilities. Research in Developmental Disabilities, 47, 430-440.

https://doi.org/10.1016/j.ridd.2015.10.009

Varsamis, P., \& Papadopoulos, A. (2014). Effects of Disability and Gender on the Per- 
ceived Reasons for Participating in Sport. The International Journal of Learning: Annual Review, 20, 95-105.

Wehmeyer, M. L., Yeager, D., Bolding, N., Agran, M., \& Hughes, C. (2003). The Effects of Self-Regulation Strategies on Goal Attainment for Students with Developmental Disabilities in General Education Classrooms. Journal of Developmental and Physical Disabilities, 15, 79-91. https://doi.org/10.1023/A:1021408405270

Wolf, E. J., Harrington, K. M., Clark, S. L., \& Miller, M. W. (2013). Sample Size Requirements for Structural Equation Models: An Evaluation of Power, Bias, and Solution Propriety. Educational and Psychological Measurement, 76, 913-934. https://doi.org/10.1177/0013164413495237

World Health Organization WHO (2007). International Classification of Functioning, Disability and Health-Child Youth Version. Geneva: WHO.

World Health Organization WHO, \& World Bank (2011)?. World Report on Disability 2011. Geneva: World Health Organization. http://www.who.int/iris/handle/10665/44575

Zhou, M. (2016). A Revisit of General Self-Efficacy Scale: Uni- or Multi-Dimensional? Current Psychology: A Journal for Diverse Perspectives on Diverse Psychological Issues, 35, 427-436. https://doi.org/10.1007/s12144-015-9311-4 